\section{B A Institute of \\ YK Business Administration \\ 六下 \\ Karachi \\ Leadership and Ideas for Tomorrow}

Business Review

Volume 13 Issue 2 July-December 2018

$1-3-2019$

\title{
Testing asset pricing models on the Pakistan Stock Exchange
}

\author{
Kiran Lohano \\ Shaheed Zulfiqar Ali Bhutto Institute of Science and Technology \\ Muhammad Kashif \\ Shaheed Zulfiqar Ali Bhutto University of Science and Technology (SZABIST), Karachi, Pakistan
}

Follow this and additional works at: https://ir.iba.edu.pk/businessreview

Part of the Finance Commons

\section{(c) (1)}

This work is licensed under a Creative Commons Attribution 4.0 International License.

\section{Recommended Citation}

Lohano, K., \& Kashif, M. (2019). Testing asset pricing models on the Pakistan Stock Exchange. Business Review, 13(2), 1-19. Retrieved from https://doi.org/10.54784/1990-6587.1027

This article is brought to you by iRepository for open access under the Creative Commons Attribution 4.0 License and is available at https://ir.iba.edu.pk/businessreview/vol13/iss2/1. For more information, please contact irepository@iba.edu.pk. 


\title{
Testing asset pricing models on the Pakistan Stock Exchange
}

\author{
Kiran Lohano • Muhammad Kashif
}

\begin{abstract}
This study investigates the performance of CAPM, three-factor and five-factor asset pricing models on the Pakistan Stock Exchange using monthly data of 896 companies from November 2000 to December 2016. The results from the time-series approach show that the three-factor model performs relatively better than the CAPM and the five-factor model, whereas the cross-sectional approach establishes the superiority of the five-factor model. It can thus be concluded that it is important to incorporate factors, such as size, value, profitability and investment when predicting returns on securities in the Pakistan Stock Exchange.
\end{abstract}

Keywords CAPM · Three-factor model · Five-factor model · Portfolio · Pakistan Stock Exchange.

\section{Introduction}

Asset pricing has been a central area of research in finance and financial economics due to its importance in examining investment decisions and predicting asset prices. To this end, many asset pricing models have been introduced, such as the mean-variance model and the capital asset pricing model (CAPM).

The mean-variance model was developed by Markowitz (1952). This model shows a trade-off between risk and returns, and thus establishes a relationship between expected returns and riskiness (variance of returns) of securities or portfolios. The CAPM was developed by Sharpe (1964) and Lintner (1965) and William Sharpe was awarded the Nobel Prize for it in 1990.

Kiran Lohano

Shaheed Zulfiqar Ali Bhutto Institute of Science and Technology (SZABIST), KarachiPakistan

E-mail: kiranlohano@gmail.com

Muhammad Kashif

Shaheed Zulfiqar Ali Bhutto Institute of Science and Technology (SZABIST), KarachiPakistan 
Although CAPM is a very popular asset pricing model, it is only a one factor model, relating the average returns of securities or portfolios to the market returns. Fama and French (1993) extended the CAPM model to include three factors related to returns. The first factor is the market factor, which is the same as in the CAPM, while the other two factors are size and value factors. They found that the overall performance of the three-factor model is better than the CAPM. More recently, Fama and French (2014) extended the three-factor model of Fama and French (1993) by adding two additional factors, namely profitability and investment factors.

Asset pricing models are used for predicting returns on alternative securities by investors, fund managers and other practitioners. As the literature on asset pricing models grows, there is a focus on testing and comparing the performance of asset pricing models, with the aim to identify a reliable model that can be used for more accurate prediction.

Fama and French (2015) tested and compared the performance of the threefactor and five-factor models. Using data from Nasdaq, they found that the overall performance of the five-factor model is better than the three-factor model. Nasdaq represents the stock market of USA. The stock market of each country is different depending on many factors, such as market structure, regulatory mechanism, institutional framework and government policies of the country. Keeping this in view, studies have been conducted testing how well these asset pricing models perform in different stock markets.

After the Fama and French (2015) study, these asset pricing models have been tested using data from China (Jiao and Lilti 2017), Japan (Kubota and Takehara 2018), Australia (Huynh 2018) and some other countries. The findings from these studies are mixed. Jiao and Lilti (2017) and Kubota and Takehara (2018) found that the three-factor model is more appropriate than the fivefactor model and adding two additional factors does not make any contribution in explaining the variation in average returns. On the other hand, like Fama and French (2015), Huynh (2018) found that the five-factor model performs relatively better than the three-factor model. In the present study, we test and compare the performance of the CAPM, three-factor and five-factor model using data from Pakistan Stock Exchange (PSX).

\section{Literature review}

This section provides a brief description of relevant literature on asset pricing models. These models include the mean-variance model, Tobin's capital market line, capital asset pricing model (CAPM), arbitrage pricing theory (APT), Fama \& French three-factor model and five-factor model.

Before the mean-variance model of Markowitz (1952), portfolios were assessed using only average returns. Investment in a portfolio was made based on the highest average returns without accounting for any risk associated with the portfolio. Markowitz (1952) challenged this idea by including the mean-variance trade off in the analysis for portfolio selection. This model provided a framework for the modern theory of portfolio management. Markowitz's model is based on 
all the risky assets while Tobin (1958) added a risk free asset with the Markowitz efficient frontier. Tobin allowed investment in assets from a mixture of risk free assets and risky assets.

The CAPM model of Sharpe (1964) and Lintner (1965) also gauged the relationship between risk and return, similar to Markowitz (1952). However, in the CAPM, the part of the risk affected by the market was detached and is called systematic risk.

At that time, researchers were trying to understand how markets determine the value of the firm and stock prices. In this context, Malkiel and Fama (1970) developed the notion of efficient markets based on the CAPM. A market is considered efficient when stock prices reflect all the available information. This notion is referred to as the efficient market hypothesis (EMH).

The CAPM has been tested empirically across the world and the results are mixed. Empirical tests were initially conducted by various authors including Friend and Blume (1970), Jensen et al (1972), and Fama and MacBeth (1973), who supported the CAPM model. Jensen et al (1972) tested the CAPM using data from New York Stock Exchange with monthly data from 1926-1966. They divided all the stocks into 10 portfolios to reduce the error in beta estimation. They tested the CAPM using time-series and cross-sectional approaches and found that there is a positive and significant slope for the security market line (SML). They also gauged that the risk-free rate moves to the higher side.

Fama and MacBeth (1973) also tested the CAPM model using data from the New York Stock Exchange. They found a positive significant relationship between average return and beta. They also found that the relationship was not perfect and concluded that there may be other factors that can affect the returns. Many other studies on the CAPM have been carried out using data from different stock markets by Basu (1983) and Bhatti and Hanif (2010) and it has been concluded that the CAPM is not sufficient.

After the CAPM, Ross (1976) developed the arbitrage pricing theory (APT), which is an asset pricing model based purely on arbitrage arguments. This model postulates that an asset's expected return is influenced by a variety of risk factors, as opposed to just market risk as assumed by the CAPM. The APT model states that the return on a security is linearly related to various systematic risk factors. However, the APT model does not specify what the systematic risk factors are.

The CAPM is a single factor model, relating the average returns of securities or portfolios to the market returns only. Fama and French (1992) explored other factors and Fama and French (1993) extended the CAPM model, and added three factors related to the returns. The first factor of the three-factor model is the market factor, which explains how the returns resemble the market portfolio. Size is considered as the second factor and it is known as SMB (small market capitalization minus big market capitalization of companies). It calculates the excess return of small capital over large capital companies. Value is the third factor of this model and it is known as HML (high book-to-market ratio minus low book-to-market ratio). This factor calculates the excess return of value stocks over growth stocks.

The three-factor model is based on these three factors, market factor, SMB

Business Review: (2018) 13(2):1-19 
and HML which together define the variation in stock returns better than the CAPM (Fama and French 1993). Many studies have been done on the threefactor model such as Eraslan (2013), and Rossi (2012). They concluded that the three-factor model is better than the CAPM.

Recently, Fama and French (2014) introduced the five-factor model by adding two additional factors, namely profitability and investment factors, to the threefactor model of (Fama and French 1993). The profitability factor is RMW (returns of firms with robust profitability minus returns of firms with weak operating profitability) and the investment factor is CMA (returns of firms that invest conservatively minus firms that invest aggressively).

Furthermore, Fama and French (2015) tested to compare the performance of the three-factor and five-factor models. Using data from the Nasdaq, they found that the overall performance of the five-factor model is better than the three-factor model. However, they pointed out that the five-factor model fails to explain very low stock returns of small firms.

The literature review shows that the asset pricing models do not consistently explain the sufficient variation in stock returns. So, researchers have been testing the validity of the asset pricing models and assessing their relative performance. After the study by Fama and French (2015), studies have been conducted on testing the performance of these models using data from different stock markets such as China Jiao and Lilti (2017), Japan Kubota and Takehara (2018), Australia Huynh (2018) and some other countries. As discussed above, these studies found that the relative performance of the three-factor model was better than the five-factor model in China and Japan, while the five-factor model performed better than the three-factor model in Australia.

Previous studies in Pakistan, using data from the PSX, found that the threefactor model performed relatively better than the CAPM (Mirza 2008; Bhatti and Hanif 2010; Hassan and Javed 2011). Haque and Sarwar (2013), using PSX data from 1998 to 2009 for 394 companies, estimated the three-factor model and included some other factors. They found that the CAPM performed better than the three-factor and other models.

Recently, Zada et al (2018) conducted an empirical study on the five-factor model using data from 2000 to 2013 for only 120 companies from the PSX. They used only selective listed companies, and hence the research was severely affected by the small sample and survivorship bias. Furthermore, they did not test the validity of the five-factor model. To our knowledge, no study has been conducted to test the validity and compare the performance of the five-factor model with the CAPM and the three-factor model using data from the PSX. In the present study, we develop portfolios using a large sample of 896 companies from 2000 to 2016, and test the validity and compare the performance of three asset pricing models: the CAPM, three-factor and five-factor model. 


\section{Research methodology}

\subsection{Data and variables}

In this study, we use monthly data of 896 companies from the PSX from November 2000 to December 2016 (194 monthly observations) collected from Thomson Reuters Datastream. ${ }^{1}$ The sample includes both dead and alive companies to keep away from the possible survival bias. Furthermore, we used a screening criteria to select the sample and included only those companies which had data for a minimum of 24 consecutive months.

In this study the dependent variable is the monthly excess rate of return of the portfolio. The explanatory variables include market, size, value, profitability and investment factors. We have used company returns to compute the portfolio excess returns. All the asset pricing models have been estimated using portfolio excess returns, as recommended in the literature (Jensen et al 1972; Dimson 1979).

Monthly excess rate of return of each company is equal to the rate of return minus the risk-free rate of return $\left(R_{i}-R_{f}\right)$. The rate of return is measured using monthly average rate of return based on closing stock price. ${ }^{2}$ The risk-free rate of return is based on T-bills returns. Market factor is the excess rate of return in the market, which is equal to market rate of return minus risk-free rate of return $\left(R_{m}-R_{f}\right)$. The market rate of return is computed using the value-weighted index of all companies listed on the PSX to represent the market portfolio.

Among the explanatory variables, the size factor is the excess rate of return on small companies over big companies, referred to as small minus big (SMB). This factor is computed as the monthly rate of return on small companies minus monthly rate of return on big companies. For grouping them, the size of the companies is based on market capitalization. The value factor is equal to the rate of return of companies with high book-to-market equity minus rate of return of companies with low book-to-market equity, referred to as high minus low (HML). For grouping them, the value of companies is based on common equity (WC03501) minus total intangibles (WC02649).

The profitability factor is equal to the rate of return of high-profitability (robust) stocks minus rate of return of low-profitability (weak) stocks, referred to as robust minus weak (RMW). For grouping the companies, the profitability is based on operating profit (WC01250) minus dividend paid (WC04551). The investment factor is equal to the rate of return of conservative (low) investment portfolios minus rate of return of aggressive (high) investment portfolios,

\footnotetext{
1 PSX computerized their records from 2000 onwards. Data before 2000 has many missing observations. So we collected data from 2000- 2016. Note that we collected data from Thomson Reuters Datastream using mnemonics. Mnemonic is a special individual code for each data series.

2 In this paper we have used monthly closing stock prices to compute the rate of returns. An alternative measure of returns is the total return index, which also accounts for dividend. However, the data on total return index had a lot of missing observations. Therefore, we did not use total return index.
} 
referred to as conservative minus aggressive (CMA). For grouping them, the investment is based on the total assets (WC02999). ${ }^{3}$

\subsection{Portfolio construction}

We construct portfolios following the approach used by (Fama and French 2015). There are five factors: market, size, value, profitability and investment factors. The size factor includes two groups: small and big market capitalization. The companies are grouped into these two categories based on the median value of market capitalization.

The value factor includes three groups: high, neutral and low value of bookto-market equity. The companies are grouped into these three categories based on top 30th percentile value, between 30th and 70th percentile value, and bottom 30th percentile value of book-to-market equity. Similarly, the profitability factor includes three groups, robust, neutral and weak, which are formed using the same percentiles as used for the value factor. Also, the investment factor includes three groups, conservative, neutral and aggressive, which are formed using the same percentiles as used for value factor.

We construct 18 portfolios. First, as there are two groups for size and three groups for value, we construct six portfolios of $2 \times 3$ sort based on size and value factors. Similarly, we construct six more portfolios of $2 \times 3$ sort based on size and profitability factors. Finally, we construct six additional portfolios of $2 \times 3$ sort based on size and investment factors. For computing the portfolio returns and factors, we compute the value-weighted returns, following the approach used by (Fama and French 2015).

\subsection{Estimation methods}

This study uses three different types of estimation methods including OLS, SURE and GMM estimators for estimating the CAPM, the three-factor model and the five-factor model. OLS estimator is most commonly used due to its simplicity and it is the best linear unbiased estimator (BLUE) (Wooldridge 2015). Another estimator is SURE, which is used when there are more than one equations to be estimated, and the error terms of these equations are correlated with each other. This estimator is particularly important for our model because there may be other unobserved common factors affecting the stock market. OLS estimates these equation individually and thus assumes no correlation among the error terms. SURE, on the other hand relaxes this assumption (Wooldridge 2015).

GMM is becoming popular due to many reasons but its main attraction is that it does not assume any distribution for the variables and error terms. Furthermore, GMM estimator is a broad method so the other methods such as OLS and instrumental variables are special cases of the GMM estimator (Kennedy 2008).

\footnotetext{
${ }^{3}$ For each factor (size, value, profitability and investment), grouping of companies was based on yearly data collected from Thomson Reuters Datastream.
} 


\subsection{Testing models}

In this study, we test the validity of the asset pricing models using two approaches, time-series approach and cross-sectional approach.

\subsubsection{Testing CAPM by the time-series approach}

Time series approach of testing the models has been used in many previous studies (Fama and French 1993, 2015). In this approach, we estimate the model using time series data.

The CAPM model is specified as follows:

$$
r_{i t}=\alpha_{i}+\beta_{i} r m_{t}+\varepsilon_{i t}
$$

where $i=1,2, I ; t=1,2,, T ; r_{i t}$ is excess return of the portfolio $i$ in month $t$; $\mathrm{rm}_{t}$ is the excess return of market in month $t ; I$ is the total number of portfolios $(I=18) ; T$ is the total number of monthly observations $(T=194)$; and $\varepsilon_{i t}$ is the random error term. The time-series regression provides estimation of $\alpha_{i}$ and $\beta_{i}$ for each portfolio.

If the CAPM is valid, then $\alpha_{i}$ should be zero. Thus, given the estimates for 18 portfolios, we conduct the following null hypothesis:

$$
H_{0}: \alpha_{1}=\alpha_{2}=\ldots=\alpha_{18}=0
$$

We test the above joint null hypothesis using three methods: OLS, SURE and GMM approach.

\subsubsection{Testing CAPM by the cross-sectional approach}

This approach of testing the models was introduced by Fama and MacBeth (1973). This approach involves two steps. The first step is to estimate the time series regressions, given in equation (1). In next step, for each month $(t)$, we run the following cross-sectional regression.

$$
r_{i t}=\lambda_{0 t}+\lambda_{1 t} \hat{\beta}_{i}+v_{i t}
$$

where $\hat{\beta}_{i}$ is the explanatory variable, estimated from equation (1) in the first step. If the CAPM is valid, then we have the following null hypotheses (Jensen et al 1972):

$$
\begin{gathered}
H_{0}: \lambda_{0}=0 \\
H_{0}: \lambda_{1}=E[\mathrm{rm}]
\end{gathered}
$$

Equation (4) is the cross-sectional version of the hypothesis given in equation (2). Taking average of equations (1) and (3), we have the relationship given in equation (5), which is tested as the null hypothesis. Jensen et al (1972) show that testing the above hypothesis is appropriate if these tests are conducted using portfolios, rather than securities. Note that the present study also uses portfolios for testing these hypotheses. Each of the above hypotheses is tested using the t test.

Business Review: (2018) 13(2):1-19 


\subsubsection{Testing the three-factor model by the time-series approach}

The three-factor model is specified as follows.

$$
r_{i t}=\alpha_{i}+\beta_{i} r m_{t}+s_{i} s m b_{t}+h_{i} h m l_{t}+\varepsilon_{i t}
$$

where $s m b_{t}$ is the size factor, SMB, in month $t$ and $h m l_{t}$ is the value factor, HML, in month $t$. The time-series regression provides estimation of $\alpha_{i}, \beta_{i}, s_{i}, h_{i}$ for each portfolio. If the three-factor model is valid, then $\alpha_{i}$ should be zero. Thus, given the estimates for 18 portfolios, we conduct the following null hypothesis:

$$
H_{0}: \alpha_{1}=\alpha_{2}=\ldots=\alpha_{18}=0
$$

We test the above joint null hypothesis using three methods: OLS, SURE and GMM approach.

\subsubsection{Testing the three-factor model by the cross-sectional approach}

Following the two steps, the first step is to estimate the time series regressions, given in equation (6). In next step, for each month $(t)$, we run the following cross-sectional regression.

$$
r_{i t}=\lambda_{0 t}+\lambda_{1 t} \hat{\beta}_{i}+\lambda_{2 t} \hat{s}_{i}+\lambda_{3 t} \hat{h}_{i}+v_{i t}
$$

where $\hat{\beta}_{i}, \hat{s}_{i}, \hat{h}_{i}$ are explanatory variables, estimated from equation (6) in the first step. If the three-factor model is valid, then we have the following null hypotheses (Jensen et al 1972):

$$
\begin{gathered}
H_{0}: \lambda_{0}=0 \\
H_{0}: \lambda_{1}=E[\mathrm{rm}] \\
H_{0}: \lambda_{2}=E[\mathrm{smb}] \\
H_{0}: \lambda_{3}=E[\mathrm{hml}]
\end{gathered}
$$

Each of the above hypotheses is tested using the t test.

\subsubsection{Testing the five-factor model by the time-series approach}

The five-factor model is specified as follows.

$$
r_{i t}=\alpha_{i}+\beta_{i} r m_{t}+s_{i} s m b_{t}+h_{i} h m l_{t}+r_{i} r m w_{t}+c_{i} c m a_{t}+\varepsilon_{i t}
$$

where $r m w_{t}$ is the profitability factor, RMW, in month $t$ and $c m a_{t}$ is the investment factor, CMA, in month $t$. The time-series regression provides estimation of $\alpha_{i}, \beta_{i}, s_{i}, h_{i}, r_{i}$ and $c_{i}$ for each portfolio. If the three-factor model is valid, 
then $\alpha_{i}$ should be zero. Thus, given the estimates for 18 portfolios, we conduct the following null hypothesis:

$$
H_{0}: \alpha_{1}=\alpha_{2}=\ldots=\alpha_{18}=0
$$

We test the above joint null hypothesis using three methods: OLS, SURE and GMM approach.

\subsubsection{Testing the five-factor model by the cross-sectional approach}

Following the two steps, the first step is to estimate the time series regressions, given in equation (13). In the next step, for each month (t), we run the following cross-sectional regression.

$$
r_{i t}=\lambda_{0 t}+\lambda_{1 t} \hat{\beta}_{i}+\lambda_{2 t} \hat{s}_{i}+\lambda_{3 t} \hat{h}_{i}+\lambda_{4 t} \hat{r}_{i}+\lambda_{5 t} \hat{c}_{i}+v_{i t}
$$

where $\beta_{i}, s_{i}, h_{i}, r_{i}$ and $c_{i}$ are explanatory variables, estimated from equation (13) in the first step. If the three-factor model is valid, we have the following null hypotheses (Jensen et al 1972):

$$
\begin{gathered}
H_{0}: \lambda_{0}=0 \\
H_{0}: \lambda_{1}=E[\mathrm{rm}] \\
H_{0}: \lambda_{2}=E[\mathrm{smb}] \\
H_{0}: \lambda_{3}=E[\mathrm{hml}] \\
H_{0}: \lambda_{4}=E[\mathrm{rmw}] \\
H_{0}: \lambda_{5}=E[\mathrm{cma}]
\end{gathered}
$$

Each of the above hypotheses is tested using the $t$ test.

\subsection{Comparing the models}

We test the hypotheses specified above for each model: CAPM, three-factor and five-factor models. Based on these hypotheses, first we determine whether the CAPM is valid or not. If it is not valid, it means that other factors should be added to explain the variation in the returns.

Furthermore, we also compare these models to determine which model performs relatively better using the method described in (Fama and French 2015). In this method, we estimate the average absolute values of the intercept (alpha) estimated in the time series regressions given above.

$$
A A V I=A\left|\hat{\alpha}_{i}\right|
$$

Business Review: (2018) 13(2):1-19 
where $A$ denotes the function for taking mean over 18 portfolios and $\hat{\alpha}_{i}$ is the estimates of intercepts from the time series regressions of 18 portfolios. We estimate equation (22) for each model: the CAPM, the three-factor model and the five-factor model using estimates from equation (1), (6) and (13), respectively. The relative performance of the model is assessed by checking which model provides the lowest value of the average absolute values of the intercept (Fama and French 2015).

\section{Results and discussion}

\subsection{Descriptive statistics}

Table 1 reports the mean, standard deviation, minimum and maximum values of the returns for each of the 18 portfolios. These 18 portfolios have different levels of the mean rate of return, which ranges from $-0.25 \%$ to $2.65 \%$. Similarly, these portfolios have different levels of risk measured by standard deviation, which ranges from $7.15 \%$ to $9.88 \%$. These portfolios have different combinations of return and risk.

The last two columns of the table show that minimum return is negative in each portfolio, and maximum return is positive in each portfolio. Table 1 also reports the t-statistics to test the null hypothesis that the mean rate of return of the portfolio is zero. The two-tailed t-test results show that 12 out of 18 portfolios have mean rate of return different from zero, and have positive mean rate of return.

\subsection{Correlation among explanatory variables}

Table 2 shows the correlation between explanatory variables for checking multicollinearity. The issue of multi-collinearity occurs when the correlation is very high. The table shows that the highest level of correlation in absolute terms is -0.389 between profitability and investment factors. The other variables have lower correlation, therefore multi-collinearity among variables is not an issue in this case.

\subsection{Testing CAPM by the time-series approach}

We estimated the CAPM using time series data from November 2000 to December 2016 for 18 portfolios, with three different types of estimation methods including OLS, SURE and GMM. Table 3 reports the estimates of the alpha coefficient (intercept) of the CAPM along with their p-values, as the validity of the CAPM is assessed based on the alpha coefficient. If the CAPM is valid, then alpha coefficient would be zero. The alpha estimate is also referred to as the pricing error. If it is greater or less than zero, it indicates that there are some other factors that are associated with the excess return. 
Testing asset pricing models...

Table 1: Descriptive statistics of portfolios

\begin{tabular}{lllllll}
\hline Portfolios & $\begin{array}{l}\text { Portfolio } \\
\text { symbols }\end{array}$ & Mean & Std. Dev & Min & Max & t-statistic \\
\hline Big Size \& Low Book-to-Market & BL & 0.005 & 0.098 & -0.454 & 0.324 & 0.719 \\
(BM) value & & & & & & \\
Big Size \& Moderate BM value & BNB & 0.015 & 0.079 & -0.436 & 0.306 & $2.617^{* * *}$ \\
Big Size \& High BM value & BH & 0.027 & 0.072 & -0.425 & 0.235 & $5.103^{* * *}$ \\
Small Size \& Low BM value & SL & -0.001 & 0.084 & -0.378 & 0.224 & -0.066 \\
Small Size \& Moderate BM value & SNB & 0.016 & 0.073 & -0.430 & 0.215 & $3.044^{* * *}$ \\
Small Size \& High BM value & SH & 0.024 & 0.098 & -0.326 & 0.450 & $3.394^{* * *}$ \\
Big Size \& Week Profitability & BW & 0.010 & 0.099 & -0.562 & 0.491 & 1.394 \\
Big Size \& Neutral profitability & BNP & 0.018 & 0.078 & -0.441 & 0.217 & $3.237^{* * *}$ \\
Big Size \& Robust Profitability & BR & 0.023 & 0.076 & -0.361 & 0.207 & $4.504^{* * *}$ \\
Small Size \& Week Profitability & SW & -0.003 & 0.095 & -0.504 & 0.284 & -0.371 \\
Small Size \& Neutral Profitability & SNP & 0.013 & 0.078 & -0.297 & 0.245 & $2.324^{* *}$ \\
Small Size \& Robust Profitability & SR & 0.022 & 0.088 & -0.356 & 0.484 & $3.520^{* * *}$ \\
Big Size \& Conservative Investment & BC & 0.013 & 0.079 & -0.437 & 0.284 & $2.323^{* *}$ \\
Big Size \& Neutral Investment & BNI & 0.020 & 0.077 & -0.416 & 0.299 & $3.557^{* * *}$ \\
Big Size \& Aggressive Investment & BA & 0.022 & 0.078 & -0.460 & 0.235 & $4.015^{* * *}$ \\
Small Size \& Conservative Invest- & SC & 0.008 & 0.093 & -0.502 & 0.438 & 1.141 \\
ment & & & & & & 0.220 \\
Small Size \& Neutral Investment & SNI & 0.002 & 0.089 & -0.539 & 0.237 \\
Small Size \& Aggressive Investment & SAI & 0.016 & 0.073 & -0.240 & 0.237 & $3.005^{* * *}$ \\
\hline
\end{tabular}

Note: Total number of monthly observations are 194. The table reports mean, standard deviation, minimum, and maximum values of portfolio rate of returns, given in proportions. The t-statistics are reported to test the null hypothesis that the mean rate of return of the portfolio is zero. *, **, and $* * *$ denote significance at 10,5 , and 1 percent, respectively.

Table 2: Correlation matrix for explanatory variables

\begin{tabular}{lccccc}
\hline Variables & RM & SMB & HML & RMW & CMA \\
\hline RM & 1.000 & & & & \\
SMB & -0.313 & 1.000 & & & \\
HML & -0.203 & 0.232 & 1.000 & & \\
RMW & -0.389 & 0.093 & 0.204 & 1.000 & \\
CMA & 0.106 & 0.223 & 0.162 & -0.361 & 1.000 \\
\hline
\end{tabular}

Note: RM: excess market returns, SMB: size factor, HML: value factor, RMW: profitability factor, CMA investment factor.

The OLS results show that, out of 18 portfolios, 9 portfolios have statistically significant values of alpha at $1 \%$ or $5 \%$ significance level. Out of these 9 portfolios, 4 portfolios have negative alpha while 5 have positive. The negative value of alpha is considered as an indication of an overvalued portfolio. With SURE and GMM, the results show that there are 10 out of 18 portfolios with statistically significant values of alpha ( 5 negative and 5 positive). These results show that the CAPM is not valid for most of the portfolios. Following Fama and French (2015), we also estimate the average absolute values of the alpha coefficient, which is equal to $0.0079(0.79 \%)$. This shows that there is $0.79 \%$ pricing error in the monthly returns.

The table also reports the results of the Wald test, which is used to test the

Business Review: (2018) 13(2):1-19 
null hypotheses that all alpha coefficients in 18 portfolios are jointly equal to zero. The Wald statistic is statistically significant as p-value is 0.000 with each estimation method: LS, SURE and GMM. Therefore, all alpha coefficients are jointly significant and are thus different from zero. This shows that CAPM is not valid, and there may be other factors associated with the excess return of the portfolios.

Table 3: Time-series estimation of CAPM

\begin{tabular}{lllllllllll}
\hline & \multicolumn{3}{c}{ OLS } & \multicolumn{3}{c}{ SURE } & \multicolumn{3}{c}{ GMM } \\
\hline $\begin{array}{l}\text { Portfolio } \\
\text { symbols }\end{array}$ & Alpha & P-val & $R^{2}$ & Alpha & P-val & $R^{2}$ & Alpha & P-val & $R^{2}$ \\
\hline BL & $-0.013^{* * *}$ & 0.002 & 0.679 & $-0.013^{* * *}$ & 0.001 & 0.679 & $-0.013^{* * *}$ & 0.001 & 0.679 \\
BNB & -0.001 & 0.799 & 0.787 & -0.001 & 0.798 & 0.787 & -0.001 & 0.809 & 0.787 \\
BH & $0.013^{* * *}$ & 0.000 & 0.728 & $0.013^{* * *}$ & 0.000 & 0.728 & $0.013^{* * *}$ & 0.000 & 0.728 \\
SL & $-0.013^{* * *}$ & 0.005 & 0.439 & $-0.013^{* * *}$ & 0.004 & 0.439 & $-0.013^{* * *}$ & 0.003 & 0.439 \\
SNB & 0.004 & 0.283 & 0.502 & 0.004 & 0.279 & 0.502 & 0.004 & 0.313 & 0.502 \\
SH & $0.015^{* *}$ & 0.028 & 0.170 & $0.015^{* *}$ & 0.026 & 0.170 & $0.015^{* *}$ & 0.021 & 0.170 \\
BW & $0-.009^{* *}$ & 0.035 & 0.701 & $0-.009^{* *}$ & 0.033 & 0.701 & $0-.009^{* *}$ & 0.044 & 0.701 \\
BNP & 0.003 & 0.304 & 0.741 & 0.003 & 0.300 & 0.741 & 0.003 & 0.337 & 0.741 \\
BR & $0.009^{* * *}$ & 0.001 & 0.724 & $0.009^{* * *}$ & 0.001 & 0.724 & $0.009^{* * *}$ & 0.001 & 0.724 \\
SW & $-0.017^{* * *}$ & 0.003 & 0.410 & $-0.017^{* * *}$ & 0.002 & 0.410 & $-0.017^{* * *}$ & 0.003 & 0.410 \\
SNP & 0.002 & 0.631 & 0.358 & 0.002 & 0.629 & 0.358 & 0.002 & 0.612 & 0.358 \\
SR & $0.012^{* *}$ & 0.035 & 0.264 & $0.012^{* *}$ & 0.033 & 0.264 & $0.012^{* *}$ & 0.035 & 0.264 \\
BC & -0.002 & 0.653 & 0.686 & -0.002 & 0.651 & 0.686 & -0.002 & 0.687 & 0.686 \\
BNI & $0.005^{*}$ & 0.095 & 0.729 & $0.005^{*}$ & 0.092 & 0.729 & $0.005^{*}$ & 0.142 & 0.729 \\
BA & $0.007^{* *}$ & 0.011 & 0.752 & $0.007^{* *}$ & 0.010 & 0.752 & $0.007^{* *}$ & 0.014 & 0.752 \\
SC & -0.004 & 0.520 & 0.278 & -0.004 & 0.517 & 0.278 & -0.004 & 0.537 & 0.278 \\
SNI & $-0.010^{*}$ & 0.073 & 0.308 & $-0.010^{*}$ & 0.070 & 0.308 & $-0.010^{*}$ & 0.072 & 0.308 \\
SAI & 0.006 & 0.195 & 0.366 & 0.006 & 0.192 & 0.366 & 0.006 & 0.190 & 0.366 \\
No of sig & 9 & & & 10 & & & 10 & & \\
alpha & & & & & & & & & \\
Wald stat & 91.341 & 0.000 & & 133.600 & 0.000 & & 142.970 & 0.000 & \\
AAVI & 0.0079 & & & 0.0079 & & & 0.0079 & & \\
\hline
\end{tabular}

Note: Number of significant alpha coefficients reported in table are based on $1 \%$ or $5 \%$ significance level. *, **, and $* * *$ denote significance at 10,5 , and 1 percent, respectively. AAVI denotes average absolute values of the intercept (alpha).

\subsection{Testing the three-factor model by the time series approach}

We estimated the three-factor model using time series data from November 2000 to December 2016 for 18 portfolios, with three different types of estimation methods including OLS, SURE and GMM. Table 4 reports the estimates of the alpha coefficient (intercept) of the three-factor model along with their p-values, as the validity of the model is assessed based on the alpha coefficient. If the three-factor model is valid, then the alpha coefficient would be zero.

The OLS results show that, out of 18 portfolios, 7 portfolios have statistically significant values of alpha at $1 \%$ or $5 \%$ significance level. With SURE and GMM, there are 9 and 10 portfolios, respectively, with statistically significant values of 
alpha. All the significant alphas have positive values. These results show that the three-factor model is not valid for around half of the portfolios. Following Fama and French (2015), we also estimate the average absolute values of the alpha coefficient, which is equal to $0.0067(0.67 \%)$. This shows that there is $0.67 \%$ pricing error in the monthly returns.

The table also reports the results of Wald test, which is used to test the

Table 4: Time-series estimation of three-factor model

\begin{tabular}{|c|c|c|c|c|c|c|c|c|c|}
\hline & OLS & & & SURE & & & GMM & & \\
\hline $\begin{array}{l}\text { Portfolio } \\
\text { symbols }\end{array}$ & Alpha & P-val & $R^{2}$ & Alpha & P-val & $R^{2}$ & Alpha & P-val & $R^{2}$ \\
\hline $\mathrm{BL}$ & -0.004 & 0.371 & 0.726 & -0.004 & 0.365 & 0.726 & -0.004 & 0.329 & 0.726 \\
\hline $\mathrm{BNB}$ & 0.005 & 0.614 & 0.791 & 0.005 & 0.610 & 0.791 & 0.005 & 0.632 & 0.791 \\
\hline $\mathrm{BH}$ & $0.012^{* * *}$ & 0.000 & 0.732 & $0.012^{* * *}$ & 0.000 & 0.732 & $0.012^{* * *}$ & 0.002 & 0.732 \\
\hline SL & 0.001 & 0.721 & 0.730 & 0.001 & 0.718 & 0.730 & 0.001 & 0.747 & 0.730 \\
\hline SNB & $0.006^{*}$ & 0.094 & 0.595 & $0.006^{*}$ & 0.089 & 0.595 & $0.006^{*}$ & 0.134 & 0.595 \\
\hline $\mathrm{SH}$ & -0.004 & 0.346 & 0.656 & -0.004 & 0.340 & 0.656 & -0.004 & 0.350 & 0.656 \\
\hline BW & -0.003 & 0.449 & 0.713 & -0.003 & 0.443 & 0.713 & -0.003 & 0.476 & 0.713 \\
\hline BNP & $0.007^{* *}$ & 0.039 & 0.753 & $0.007^{* *}$ & 0.036 & 0.753 & $0.007 * *$ & 0.055 & 0.753 \\
\hline $\mathrm{BR}$ & $0.008^{* *}$ & 0.012 & 0.728 & $0.008^{* *}$ & 0.010 & 0.728 & $0.008^{* *}$ & 0.020 & 0.728 \\
\hline SW & -0.008 & 0.130 & 0.578 & -0.008 & 0.124 & 0.578 & -0.008 & 0.177 & 0.578 \\
\hline SNP & $0.007^{*}$ & 0.093 & 0.555 & $0.007^{*}$ & 0.088 & 0.555 & $0.007^{*}$ & 0.087 & 0.555 \\
\hline SR & $0.020 * * *$ & 0.000 & 0.443 & $0.020 * * *$ & 0.000 & 0.443 & $0.020^{* * *}$ & 0.001 & 0.443 \\
\hline $\mathrm{BC}$ & 0.003 & 0.463 & 0.699 & 0.003 & 0.457 & 0.699 & 0.003 & 0.502 & 0.699 \\
\hline $\mathrm{BNI}$ & $0.007^{* *}$ & 0.033 & 0.732 & $0.007^{* *}$ & 0.030 & 0.732 & $0.007 * *$ & 0.053 & 0.732 \\
\hline $\mathrm{BA}$ & $0.008^{* *}$ & 0.015 & 0.753 & $0.008^{* *}$ & 0.013 & 0.753 & $0.008^{* *}$ & 0.023 & 0.753 \\
\hline $\mathrm{SC}$ & -0.004 & 0.425 & 0.546 & -0.004 & 0.419 & 0.546 & -0.004 & 0.529 & 0.546 \\
\hline SNI & -0.004 & 0.519 & 0.412 & -0.004 & 0.513 & 0.412 & -0.004 & 0.539 & 0.412 \\
\hline SAI & $0.014^{* * *}$ & 0.001 & 0.548 & $0.014^{* * *}$ & 0.001 & 0.548 & $0.014^{* * *}$ & 0.000 & 0.548 \\
\hline $\begin{array}{l}\text { No of sig } \\
\text { alpha }\end{array}$ & 7 & & & 7 & & & 6 & & \\
\hline Wald stat & 72.636 & 0.000 & & 74.900 & 0.000 & & 75.510 & 0.000 & \\
\hline AAVI & 0.0067 & & & 0.0067 & & & 0.0067 & & \\
\hline
\end{tabular}

Note: Number of significant alpha coefficients reported in the table are based on $1 \%$ or $5 \%$ significance level. *, **, and *** denote significance at 10, 5, and 1 percent, respectively. AAVI denotes average absolute values of the intercept (alpha).

null hypotheses that all alpha coefficients in 18 portfolios are jointly equal to zero. The Wald statistic is statistically significant as p-value is 0.000 with each estimation method: LS, SURE and GMM. Therefore, all alpha coefficients are jointly significant and are thus different from zero. This shows that the threefactor model is not valid. Our results are similar to the findings in other studies, such as (Basu 1983; Bhatti and Hanif 2010; Hassan and Javed 2011).

The above results show that, like the CAPM, the three factor model is also not valid. However, we need to asses which model performs relatively better. The three-factor model has lower number of significant values of alpha as compared to the CAPM. Moreover, the average absolute values of alpha coefficient, a proxy of pricing error, is lower in the three-factor model as compared to CAPM. Thus, these results show that the three-factor model performs relatively better than CAPM.

Business Review: (2018) 13(2):1-19 
4.5 Testing the five-factor model by the time-series approach

We estimated the five-factor model using time series data from November 2000 to December 2016 for 18 portfolios, with three different types of estimation methods including OLS, SURE and GMM. Table 5 reports the estimates of the alpha coefficient (intercept) of the five-factor along with their p-values, as the validity of the five-factor is assessed based on the alpha coefficient. If the five-factor model is valid, then alpha coefficient would be zero.

The OLS results show that, out of 18 portfolios, 11 portfolios have statistically significant values of alpha at $1 \%$ or $5 \%$ significance level. In SURE and GMM there are 12 and 11 portfolios, respectively, with statistically significant values of alpha. All the significance alphas have positive value. These results show that the five-factor model is not valid for most of the portfolios. Following Fama and French (2015), we also estimate the average absolute values of the alpha coefficient, which is equal to $0.0076(0.76 \%)$. This shows that there is $0.76 \%$ pricing error in the monthly returns.

The table also reports the results of the Wald test, which is used to test the null hypotheses that all alpha coefficients in 18 portfolios are jointly equal to zero. The Wald statistic is statistically significant as p-value is 0.000 with each estimation method: LS, SURE and GMM. Therefore, all alpha coefficients are jointly significant and are thus different from zero. This shows that the fivefactor model is not valid, and there may be other factors associated with the excess return of the portfolios. Our results are similar to the findings in other studies like (Jiao and Lilti 2017; Kubota and Takehara 2018; Zada et al 2018.

The above results show that, like the CAPM and the three factor model, the five-factor model is also not valid. However, we need to asses which model performs relatively better. The three-factor model has the lowest number of significant values of alpha as compared to the CAPM and five-factor model. Moreover, the average absolute values of alpha coefficient, a proxy of pricing error, is lowest in the three-factor model as compared to the other model. Thus, these results show that the three-factor model performs relatively better than the CAPM and the five-factor model based on the time-series testing approach.

\subsection{Testing CAPM by the cross-sectional approach}

Table 6 presents the results for testing CAPM by the cross-sectional approach Fama and MacBeth (1973). This approach estimates the average value of excess market returns $(\lambda)$ by running the time series regression and cross sectional regression, as explained in the methodology section. In this approach, the last step is to test the null hypothesis that the average value of $\lambda_{1}$ is equal to the average value of actual excess market returns, which would indicate the validity of CAPM.

Table 6 reports the average value of $\lambda_{1}(-0.006)$, and the actual average value of excess market returns (0.017) along with the results of the t test for the null hypothesis. As the p-value is less than 0.01 , the test rejects the null hypothesis 
Testing asset pricing models...

Table 5: Time-series estimation of five-factor model

\begin{tabular}{|c|c|c|c|c|c|c|c|c|c|}
\hline & \multicolumn{3}{|c|}{ OLS } & \multicolumn{3}{|c|}{ SURE } & \multicolumn{3}{|c|}{ GMM } \\
\hline $\begin{array}{l}\text { Portfolio } \\
\text { symbols }\end{array}$ & Alpha & P-val & $R^{2}$ & Alpha & P-val & $R^{2}$ & Alpha & P-val & $R^{2}$ \\
\hline $\mathrm{BL}$ & 0.001 & 0.855 & 0.732 & 0.001 & 0.852 & 0.732 & 0.001 & 0.851 & 0.732 \\
\hline BNB & $0.006^{* *}$ & 0.039 & 0.811 & $0.006^{* *}$ & 0.035 & 0.811 & $0.006^{* *}$ & 0.059 & 0.811 \\
\hline $\mathrm{BH}$ & $0.013^{* * *}$ & 0.000 & 0.738 & $0.013^{* * *}$ & 0.000 & 0.738 & $0.013^{* * *}$ & 0.002 & 0.738 \\
\hline SL & 0.006 & 0.110 & 0.754 & 0.006 & 0.103 & 0.754 & 0.006 & 0.135 & 0.754 \\
\hline SNB & $0.010^{* *}$ & 0.010 & 0.612 & $0.010^{* *}$ & 0.008 & 0.612 & $0.010^{* *}$ & 0.016 & 0.612 \\
\hline $\mathrm{SH}$ & 0.003 & 0.529 & 0.689 & 0.003 & 0.522 & 0.689 & 0.003 & 0.536 & 0.689 \\
\hline BW & 0.006 & 0.222 & 0.755 & 0.006 & 0.213 & 0.755 & 0.006 & 0.303 & 0.755 \\
\hline BNP & $0.011^{* * *}$ & 0.002 & 0.768 & $0.011 * * *$ & 0.001 & 0.768 & $0.011^{* * *}$ & 0.004 & 0.768 \\
\hline $\mathrm{BR}$ & $0.006^{*}$ & 0.057 & 0.731 & $0.006^{*}$ & 0.052 & 0.731 & $0.006^{*}$ & 0.102 & 0.731 \\
\hline SW & $0.009 * *$ & 0.027 & 0.777 & $0.009^{* *}$ & 0.023 & 0.777 & $0.009^{* *}$ & 0.033 & 0.777 \\
\hline SNP & $0.011^{* *}$ & 0.018 & 0.569 & $0.011^{* *}$ & 0.015 & 0.569 & $0.011^{* *}$ & 0.013 & 0.569 \\
\hline SR & 0.005 & 0.290 & 0.644 & 0.005 & 0.281 & 0.644 & 0.005 & 0.360 & 0.644 \\
\hline $\mathrm{BC}$ & $0.010^{* * *}$ & 0.005 & 0.756 & $0.010 * * *$ & 0.004 & 0.756 & $0.010^{* * *}$ & 0.009 & 0.756 \\
\hline BNI & $0.010^{* * *}$ & 0.005 & 0.739 & $0.010 * * *$ & 0.004 & 0.739 & $0.010 * * *$ & 0.021 & 0.739 \\
\hline BA & $0.008 * *$ & 0.016 & 0.759 & $0.008 * *$ & 0.014 & 0.759 & $0.008 * *$ & 0.020 & 0.759 \\
\hline $\mathrm{SC}$ & $0.013 * * *$ & 0.001 & 0.781 & $0.013^{* * *}$ & 0.001 & 0.781 & $0.013^{* * *}$ & 0.004 & 0.781 \\
\hline SNI & 0.001 & 0.876 & 0.426 & 0.001 & 0.874 & 0.426 & 0.001 & 0.863 & 0.426 \\
\hline SAI & $0.011^{* * *}$ & 0.006 & 0.643 & $0.011 * * *$ & 0.005 & 0.643 & $0.011 * * *$ & 0.006 & 0.643 \\
\hline $\begin{array}{l}\text { No of sig } \\
\text { alpha }\end{array}$ & 11 & & & 11 & & & 10 & & \\
\hline Wald stat & 97.620 & 0.000 & & 45.900 & 0.000 & & 45.080 & 0.000 & \\
\hline AAVI & 0.0077 & & & 0.0077 & & & 0.0077 & & \\
\hline
\end{tabular}

Note: Number of significant alpha coefficients reported in the table are based on $1 \%$ or $5 \%$ significance level. $*, * *$, and $* * *$ denote significance at 10,5 , and 1 percent, respectively. AAVI denotes average absolute values of the intercept (alpha).

at 1 percent significance level. Furthermore, if the CAPM is valid, then the intercept coefficient $\lambda_{0}$ should be zero. If the intercept is not zero, it indicates that there are some other factors that are associated with the excess return. Table 6 also reports that the value of intercept is 0.019 with t-statistic 2.308 for the null hypothesis that the intercept is zero. As the p-value is less than .05 , the test rejects the null hypothesis at 5 percent significance level. Therefore, these tests fail to prove the validity of CAPM in the Pakistan stock market.

Table 6: Testing CAPM by cross-sectional approach

\begin{tabular}{lcccccc}
\hline Factor & Parameter & $\begin{array}{l}\text { Mean } \\
\text { value }\end{array}$ & Factor & $\begin{array}{l}\text { Mean } \\
\text { value }\end{array}$ & $\begin{array}{c}\text { Difference } \\
(\lambda \text { - factor })\end{array}$ & $\begin{array}{c}\text { t-statistic } \\
(\text { P-val })\end{array}$ \\
\hline Market & $\lambda_{1}$ & -0.006 & RM & 0.017 & -0.023 & $\begin{array}{c}-2.625^{* * *} \\
(0.010)\end{array}$ \\
Intercept & $\lambda_{0}$ & 0.019 & & & & $\begin{array}{c}2.308^{* *} \\
(0.022)\end{array}$ \\
\hline
\end{tabular}

Note: ${ }^{* *}$ and ${ }^{* * *}$ denote significant at 5 and 1 percent, respectively. P-value of t-statistic is reported in parenthesis. 
4.7 Testing the three-factor model by the cross-sectional approach

Table 7 presents the results for testing the three-factor model by the crosssectional approach. In this model, we have estimations for three factors: $\lambda_{1}$ for excess market return (market factor), $\lambda_{2}$ for excess return of small companies over big companies (size factor), and $\lambda_{3}$ for excess return of high book-to-market equity over low book-to-market equity (value factor).

Table 7 reports the average value of $\lambda_{1}(-0.041)$, and the average value of actual excess market returns (0.017) along with the results of the test for the null hypothesis that the average value of $\lambda_{1}$ is equal to the average of value of actual excess market returns. As the p-value is less than 0.01, the test rejects the null hypothesis at 1 percent significance level.

The table reports the average value of $\lambda_{2}(-0.012)$ and the average value of size factor $(-0.003)$ along with the results of the t test for the null hypothesis that they are equal. As the p-value is less than 0.01, the test rejects the null hypothesis at 1 percent significance level. The average value of $\lambda_{3}(0.018)$ and the average value of value factor $(0.021)$ are also reported along with the results of the $t$ test for the null hypothesis that they are equal. As the p-value is less than 0.1 , the test rejects the null hypothesis at 10 percent significance level. This is only one value factor, which shows a little relationship between systematic risk and book-to market equity at 10 percent level. Remaining two results show that both are not equal.

In this model, the average value of lambda and factor should be equal, but the results are different from the theory and do not prove the relationship between lambdas and factors. Furthermore, if the three-factor model is valid, then the intercept coefficient $\lambda_{0}$ should be zero. If the intercept is not equal to zero, it indicates that there are some other factors that are associated with the excess return. Table 7 also reports that the value of intercept is 0.057 with t-statistic 6.919 for the null hypothesis that the intercept is zero. As the p-value is less than .01, the test rejects the null hypothesis at 1 percent significance level. Therefore, these tests fail to prove the validity of the three-factor model in the Pakistan stock market.

Table 7: Testing three-factor model by cross-sectional approach

\begin{tabular}{|c|c|c|c|c|c|c|}
\hline Factor & Parameter & $\begin{array}{l}\text { Mean } \\
\text { value }\end{array}$ & Factor & $\begin{array}{l}\text { Mean } \\
\text { value }\end{array}$ & $\begin{array}{l}\text { Difference } \\
(\lambda-\text { factor })\end{array}$ & $\begin{array}{l}\text { t-statistic } \\
(\mathrm{P} \text {-val) }\end{array}$ \\
\hline Market & $\lambda_{1}$ & -0.041 & $\mathrm{RM}$ & 0.017 & -0.058 & $\begin{array}{c}-5.932^{* * *} \\
(0.000)\end{array}$ \\
\hline Size & $\lambda_{2}$ & -0.012 & SMB & -0.003 & -0.008 & $\begin{array}{c}-4.204^{* * *} \\
(0.000)\end{array}$ \\
\hline Value & $\lambda_{3}$ & 0.018 & HML & 0.021 & -0.003 & $\begin{array}{c}-1.660^{*} \\
(0.099)\end{array}$ \\
\hline Intercept & $\lambda_{0}$ & 0.057 & & & & $\begin{array}{c}6.919 * * * \\
(0.000)\end{array}$ \\
\hline
\end{tabular}

Note: $*$, and $* * *$ denote significance at $10, \& 1$ percent, respectively. P-value of t-statistic is reported in parenthesis. 
Testing asset pricing models...

\begin{tabular}{|c|c|c|c|c|c|c|}
\hline Factor & Parameter & $\begin{array}{l}\text { Mean } \\
\text { value }\end{array}$ & Factor & $\begin{array}{l}\text { Mean } \\
\text { value }\end{array}$ & $\begin{array}{l}\text { Difference } \\
(\lambda \text { - factor })\end{array}$ & $\begin{array}{l}\text { t-statistic } \\
(\mathrm{P} \text {-val })\end{array}$ \\
\hline Market & $\lambda_{1}$ & -0.012 & $\mathrm{RM}$ & 0.017 & -0.029 & $\begin{array}{r}-2.513^{* *} \\
(0.012)\end{array}$ \\
\hline Size & $\lambda_{2}$ & -0.008 & SMB & -0.003 & -0.004 & $\begin{array}{r}-2.225^{* *} \\
(0.027)\end{array}$ \\
\hline Value & $\lambda_{3}$ & 0.02 & HML & 0.021 & -0.001 & $\begin{array}{c}-0.586 \\
(0.558)\end{array}$ \\
\hline Profitability & $\lambda_{4}$ & 0.021 & RMW & 0.019 & 0.002 & $\begin{array}{c}1.556 \\
(0.121)\end{array}$ \\
\hline Investment & $\lambda_{5}$ & -0.009 & CMA & -0.009 & 0.001 & $\begin{array}{c}0.645 \\
(0.519)\end{array}$ \\
\hline Intercept & $\lambda_{0}$ & 0.033 & & & & $\begin{array}{r}3.507^{* * *} \\
(0.000)\end{array}$ \\
\hline
\end{tabular}

Note: ${ }^{* *}$ and ${ }^{* * *}$ denote significance at 5 and 1 percent, respectively. P-value of t-statistic is reported in parenthesis.

4.8 Testing the five-factor model by the cross-sectional approach

Table 8 presents the results for testing the five factor model by the crosssectional approach. In this model, we have estimations for five factors: $\lambda_{1}$ for excess market return (market factor), $\lambda_{2}$ for excess return of small companies over big companies (size factor), $\lambda_{3}$ for excess return of high book-to-market equity over low book-to-market equity (value factor), $\lambda_{4}$ for excess return of high-profitability stocks over low-profitability stocks (profitability factor) and $\lambda_{5}$ for excess return of conservative investment portfolios over aggressive investment portfolios (investment factor).

Table 8 reports the average value of lambda and the average of actual value of the factor for each of the five factors, and reports the $t$ test results for testing the null hypothesis that the average value of lambda is equal to the average of actual value of factor. The results show that the null hypothesis for the first two factors (market and size factor) is rejected at $5 \%$ percent significance level, and the hypothesis is not rejected for the remaining three factors. These results show that equality of lambda and the factor is supported in the model for three out of five factors, showing some evidence of the validity of the five factor model.

Furthermore, table 8 also reports that the value of the intercept is 0.033 with t-statistic 3.507 for the null hypothesis that the intercept is zero. As the $\mathrm{p}$-value is less than .01, the test rejects the null hypothesis at 1 percent significance level. Therefore, the results of this test do not support the validity of the five-factor model in the PSX.

\section{Conclusion}

This study tests the validity of the CAPM, three-factor and five-factor models in the Pakistan stock exchange using monthly data from November 2000 to December 2016. We construct 18 portfolios using data for 896 companies. 
Two types of testing models are used namely time-series and cross sectional approaches. As these models are estimated using excess rate of return of portfolio and market factors, the alpha coefficient (intercept) in these models would be zero if the model is valid.

The results from the time series approach show that the average absolute values of alpha coefficient are $0.79 \%, 0.67 \%$, and $0.77 \%$ in CAPM, three-factor and five-factor models, respectively. The average absolute value of the alpha coefficient is an indicator of the overall pricing error. Following Fama and French (2015), we find that the three-factor model has the lowest average absolute value of alpha coefficient as compared to the other two models. Furthermore, the Wald statistic is the lowest in the three-factor model among all models. Thus, the time-series approach shows that the three-factor model performs relatively better than the CAPM and the five-factor model.

Using the cross-sectional approach, we first test the hypothesis that the intercept is zero, and find that the $t$ test rejects the null hypothesis, showing that none of the models is valid. Furthermore, we assess the models based on the hypothesis that the average value of the estimated parameter is equal to the average of actual value of factor. This hypothesis is rejected for its one factor in the CAPM, and it is rejected for two out three factors in the three-factor model based on 1 or 5 per cent significance level. In the case of the five-factor model, the hypothesis is rejected for two out of five factors. This shows that the five-factor model is relatively better based on the cross-sectional approach of testing.

The findings of this study show that the three-factor model performs better than the CAPM and five factor model based on the time-series approach, while the five-factor model performs better than the other two models based on the cross-sectional approach for the Pakistan stock exchange. Thus, multi-factor models are relatively more accurate than CAPM. These findings have important implications for investors, fund managers and other practitioners, and suggest the importance of incorporating multiple factors for predicting the returns of securities.

\section{References}

Basu S (1983) The relationship between earnings' yield, market value and return for nyse common stocks: Further evidence. Journal of Financial Economics 12(1):129-156

Bhatti U, Hanif M (2010) Validity of capital assets pricing model: Evidence from kse-pakistan

Dimson E (1979) Risk measurement when shares are subject to infrequent trading. Journal of Financial Economics 7(2):197-226

Eraslan V (2013) Fama and french three-factor model: Evidence from istanbul stock exchange. Business and Economics Research Journal 4(2):11

Fama E, French K (2014) A five-factor asset pricing model, fama-miller working paper

Fama EF, French KR (1992) The cross-section of expected stock returns. The Journal of Finance 47(2):427-465

Fama EF, French KR (1993) Common risk factors in the returns on stocks and bonds. Journal of Financial Economics 33(1):3-56

Fama EF, French KR (2015) Incremental variables and the investment opportunity set. Journal of Financial Economics 117(3):470-488

Fama EF, MacBeth JD (1973) Risk, return, and equilibrium: Empirical tests. Journal of Political Economy 81(3):607-636 
Friend I, Blume M (1970) Measurement of portfolio performance under uncertainty. The American Economic Review 60(4):561-575

Haque A, Sarwar S (2013) Effect of fundamental and stock market variables on equity return in pakistan. Science International 25(4)

Hassan A, Javed MT (2011) Size and value premium in pakistani equity market. African Journal of Business Management 5(16):6747-6755

Huynh TD (2018) Explaining anomalies in australia with a five-factor asset pricing model. International Review of Finance 18(1):123-135

Jensen MC, Black F, Scholes MS (1972) The capital asset pricing model: Some empirical tests

Jiao W, Lilti JJ (2017) Whether profitability and investment factors have additional explanatory power comparing with fama-french three-factor model: Empirical evidence on chinese a-share stock market. China Finance and Economic Review 5(1):7

Kennedy P (2008) A guide to modern econometrics

Kubota K, Takehara H (2018) Does the fama and french five-factor model work well in japan? International Review of Finance 18(1):137-146

Lintner J (1965) Security prices, risk, and maximal gains from diversification. The Journal of Finance 20(4):587-615

Malkiel BG, Fama EF (1970) Efficient capital markets: A review of theory and empirical work. The Journal of Finance 25(2):383-417

Markowitz H (1952) Portfolio selection. The Journal of Finance 7(1):77-91

Mirza N (2008) Size and value premium in karachi stock exchange

Ross S (1976) The arbitrage theory of capital asset pricing

Rossi F (2012) The three-factor model: Evidence from the italian stock market. Research Journal of Finance and Accounting 3(9):151-160

Sharpe WF (1964) Capital asset prices: A theory of market equilibrium under conditions of risk. The Journal of Finance 19(3):425-442

Tobin J (1958) Liquidity preference as behavior towards risk. The Review of Economic Studies $25(2): 65-86$

Wooldridge JM (2015) Introductory econometrics: A modern approach. Nelson Education

Zada H, Rehman MU, Khwaja MG (2018) Application of fama and french five factor model of asset pricing: Evidence from pakistan stock market. International Journal of Economics, Management and Accounting 26(1):1-23

Business Review: (2018) 13(2):1-19 